\title{
O AMOR E AS RELAÇÕES AFETIVAS NA CONTEMPORANEIDADE - UMA PROPOSTA ÉTICA, ESTÉTICA E POLÍTICA
}

\author{
LOVE AND AFFECTIVE RELATIONS ON CONTEMPORANEITY - AN ETHICAL, \\ AESTHETIC AND POLITICAL PROPOSAL
}

\author{
Josiane Cristina Orlando de Souza ${ }^{1}$
}

\begin{abstract}
Resumo: Na contemporaneidade vivemos um modo característico de produção da subjetividade, a saber, a subjetividade capitalística. Tal subjetividade afeta a maneira como produzimos afetos e relacionamentos em nossa vida. Torna-se necessário compreender estas afetações e agenciar novos modos de experimentar o amor em sua potência. Apresentamos uma proposta baseada na ética de Espinosa, na estética da existência de Foucault e na micropolítica de Deleuze e Guattari.
\end{abstract}

Palavras-chave: Amor; subjetividade; capitalismo.

\begin{abstract}
On contemporaneity we live a characteristic way of subjectivity production, namely, the capitalistic subjectivity. This subjectivity influences how we produce affections and relationships in our lives. Becomes necessary comprehend those affectations and agency new ways of experiencing love in its potency. We presente a proposal based on Espinosa's ethical, Foucault's aesthetics of existence and on Deleuze and Guattari's micropolitics.
\end{abstract}

Keywords: Love; subjectivity; capitalism.

Então o amor anda impossível? Nem tanto.

Suely Rolnik

O que pode o amor? O que pode um corpo afetado pelas intensidades do amor?

Iniciamos este artigo com o objetivo de refletir sobre questões referentes à potencialidade do amor e sobre modos possíveis de experimentá-la nos relacionamentos afetivos da contemporaneidade.

Atualmente vivemos modos de produção de afetos e relacionamentos ainda calcados no modelo romântico europeu iniciado em meados do século XVIII. Sabemos que o Romantismo, enquanto movimento artístico, político e filosófico influenciou intensamente a noção de amor da época, estabelecendo o ideal do amor romântico.

Ainda hoje não é incomum lidarmos com a ideia de que o amor é um sentimento natural e espontâneo, que chega sem aviso e sem motivo, arrebatando os corações apaixonados; ou ainda, que seja possível encontrar a tão sonhada "alma gêmea", a "metade da laranja" que está por aí e que, em algum momento, se apresentará como o verdadeiro e único amor. Ademais, espera-se que desse encontro possa constituir-se, também, a tão desejada "família feliz", sendo o ápice da união do casal e a concretude do projeto comum de felicidade.

Todos esses ideais fortemente introjetados pela sociedade europeia e, difundidos para o restante do ocidente, ainda interferem diretamente na compreensão que temos a respeito do amor e dos modos de experimentá-lo e vivenciá-lo em nossos relacionamentos afetivos.

Entretanto, o amor, assim como qualquer outro sentimento, é passível de ser experimentado de acordo com cada época, cultura ou sociedade, ou seja, o amor e os modos de amar não são naturais, pois obedecem aos interesses e determinantes de cada período histórico.

\footnotetext{
${ }^{1}$ Universidade de São Paulo (FFCLRP), Uberaba. E-mail: psi.josianesouza@gmail.com.
} 
Tais ideais românticos sustentam o que o psicanalista Jurandir Freire Costa defende como sendo o "credo amoroso", a saber, o amor enquanto sentimento universal e natural, surdo à voz da razão e condição sine qua non da máxima felicidade.

Segundo Costa (1998), a busca incansável pela experiência desse amor romântico tem gerado, ao longo dos tempos, uma enorme frustração àqueles que não conseguem, e até mesmo aos que acreditam ter conseguido, pois de qualquer modo, temem pela sua efemeridade.

Sentem-se ainda mais "frustrados" porque a sociedade lhes imputa um 'fracasso pessoal', de não saberem encontrar o seu objeto ideal de amor e de não poderem vivenciar um ato humano tão simples, universal e sublime; um algo 'aparentemente ao alcance de qualquer pessoa razoavelmente adulta, madura, sem inibições afetivas ou impedimentos culturais' (Costa, 1998, p. 35).

Deste modo, não é difícil chegar até os consultórios de psicologia inúmeras queixas relacionadas às questões amorosas, como autoestima baixa, insegurança, pavor da solidão, depressão e vários outros sofrimentos emocionais.

Os adoecimentos emocionais encontram sua causa no sistema neoliberal vigente, pois o neoliberalismo ao intitular o indivíduo como empreendedor de si mesmo, diante de uma sociedade que exige cada vez mais competências, atribui exclusivamente a este, a responsabilidade pelo seu sucesso ou fracasso, seja econômico ou emocional. Encontrar um amor e construir a família feliz e também empreendedora que formará o capital humano desejável ao desenvolvimento da economia e do mercado, passa a ser imperativo, e quando não alcançado, o indivíduo só pode culpar a si mesmo.

Segundo Takeuti (2015), o colonialismo europeu não se deu somente a níveis político e econômico, mas principalmente ao nível da produção de subjetividade. Alicerçada pelas ideias de Foucault a respeito dos dispositivos de poder na construção do projeto de Modernidade, a autora defende que o colonialismo europeu enquanto colonialidade de poder englobou todas as esferas da vida, inclusive a subjetividade e os modos de amar.

Cabe realçar que não pretendemos deter nossa análise na relação entre o colonialismo europeu e o projeto de modernidade ${ }^{2}$, ou mesmo sobre os dispositivos de poder foucaultianos lembrados pela autora, e sim nos apoiarmos na sua ideia de "colonialidade do amor".

[...] o essencial disso que chamo de colonialidade do amor, isto é, a ideia de que aí há tanto mais o domínio da razão, do cálculo e dos interesses econômicos, quanto menos o domínio da emoção pura, da sentimentalidade e da espontaneidade, como os idealistas do amor romântico fazem crer (Takeuti, 2015, p. 69).

O amor colonizado, então, funciona como modelo dominante para as relações afetivas, se configurando como forte aliado aos interesses neoliberais e capitalistas de nossa época.

Segundo Guattari, a "máquina capitalística produz (...) aquilo que acontece conosco quando sonhamos, quando devaneamos, quando fantasiamos, quando nos apaixonamos e assim por diante. (...)" (GUATTARI; ROLNIK, 2005, p. 22).

Ao capitalismo interessa apenas a expansão econômica, estando as mercadorias subordinadas a este objetivo, portanto, tanto os objetos de consumo quanto a própria subjetividade, se tornaram meios indispensáveis para sua expansão, lembrando, nesse sentido, a afirmação de Guattari e Rolnik (2005) de que a subjetividade atualmente é mais valiosa do que o petróleo.

\footnotetext{
${ }^{2}$ Takeuti (2015) explicita que tal relação vem sendo discutida pelos teóricos da perspectiva decolonial na América Latina.
} 
A hegemonia do capitalismo atual alcança não só a dimensão da produção da economia mundial, mas também a produção da subjetividade para conservar sua reprodução. Este sistema é o que Guattari chama de Capitalismo Mundial Integrado (CMI).

Para Baremblitt (2006), o Capitalismo Mundial Integrado está no âmago da produção de subjetividades, produzindo acentuadamente subjetividades assujeitadas e adormecendo a produção de subjetivações livres e mutativas.

A produção dominante de subjetividades reprodutivas e antiprodutivas que correspondem a essa configuração mundial, não podem senão ter como seu eixo principal a servidão a esse Amo, ou sua descartabilidade para esses fins. As subjetividades que empiricamente chamamos "individuais", "de grupo", "de organização", de "classe" que sirvam para esses fins, tem toda a liberdade constitucional para entrar no jogo para o qual foram feitas, e podem fazê-lo respeitando as regras do mesmo, ou desrespeitando-as, sempre que tenham poder e a astúcia suficiente (BAREMBLITT, 2006, p. 16).

O capital, no interior da própria produção, produz subjetividades faltosas, desejos eternamente insatisfeitos, capturando o desejo no íntimo teatral e familiar, operando pela via da privatização da subjetividade, na medida em que “ (...) acarretam menos numa publicização do privado do que numa privatização do público: o mundo inteiro se passa em família, sem que se tenha que deixar a sua televisão" (DELEUZE; GUATTARI, 2010, p. 332).

Este funcionamento do capital tem, conforme Guattari e Rolnik (2005), reduzido a experiência amorosa a uma apropriação do corpo, imagem e devir do outro, não o sentindo como companheiro de partilha, mas como uma propriedade privada, da qual se toma posse.

Para Guattari e Rolnik (2005) a influência do capital no modo de amar na atualidade tem alcançado dois extremos: o primeiro é o da relação especular, o apego excessivo que gera simbiose familialista sufocante e tóxica, e o segundo são as máquinas celibatárias, sem territórios fixos, que vivem de desterritorializações ou intensidades puras que fragilizam e se desmancham no ar.

Podemos dizer que o primeiro modo de amar citado por Guattari e Rolnik, se refere ao amor romântico colonizado, em que na tentativa exaustiva de garantir a felicidade e o sucesso do casal, são lançados mecanismos de apropriação, sujeição, apego e dependência que, por sua vez, geram intensos estados de insegurança, ciúmes e medo.

O exemplo do amor livre, tão comentado e vivido atualmente, principalmente na era das redes sociais, se aplica facilmente ao segundo modo de amar elencado pela autora. $\mathrm{O}$ outro, encontrado na prateleira dos inúmeros aplicativos, é descartável. $\mathrm{O}$ encontro se torna uma aventura no campo das sensações, mas não permite memória e nem história, pois "a fila anda" e logo adiante há a possibilidade de mais um gozo fútil e passageiro.

Amor livre enquanto máquina celibatária, pois neste caso não é um modo de amar que pressuponha a liberdade, mas ao contrário, um tipo de amor livre de consistência, livre de composição de territórios, livre de pouso que permita voos potentes.

Guattari e Rolnik (2005) alerta que ambos os modos extremos de amar e se relacionar são perigosos, pois enfraquecem os agenciamentos do desejo e até mesmo a produção de novos territórios de vida.

Sobre essa questão, Rolnik (1989) destaca que o desejo é atravessado por três linhas, as quais denomina "linhas da vida". A primeira delas é a dos afetos invisíveis e inconscientes, que escapam e criam linhas de fuga, que não significam fugir do mundo, mas fugir, desmanchar territórios e criar outros possíveis. A segunda linha é a da simulação, que se encontra entre a primeira e a terceira linha, ou seja, entre as linhas de fuga criadas pelos afetos e as linhas de territorialização. Esta segunda linha, por funcionar de modo ambíguo e intermediário, tende a gerar angústia. 
Pelo fato de a ambigüidade ser inerente a essa linha, e por isso mesmo insuperável, há sempre uma angústia pairando no ar. Angústia que tem uma face ontológica (medo de a vida se desagregar, de ela não conseguir perseverar, medo de morrer); uma face existencial (medo de a forma de exteriorização das intensidades perder credibilidade, ou seja, de certos mundos perderem legitimidade, desabarem, medo de fracassar); uma face psicológica (medo de perder forma tal como vivida pelo ego, medo de enlouquecer) (ROLNIK, 1989, p. 49).

A terceira linha, como já mencionado, é a das reterritorializações, do retorno aos territórios a nível visível e consciente. Retorno ao plano de consistência, à terra firme.

Rolnik (1989) realça que toda produção do desejo no campo social se dá a partir do emaranhado de tais linhas, pois são imanentes umas às outras.

Entretanto, há um perigo iminente caso haja estagnação em uma das linhas.

Diante do modo de amar desterritorializante das máquinas celibatárias, que seria a primeira linha ou linha dos afetos, e do modo de amar romântico e colonizado que gera simbiose, que seria a terceira linha de reterritorialização, em que se pode transitar vez ou outra, nos deparamos com um profundo sofrimento emocional gerado pela ideia de insucesso amoroso. A culpa e a insegurança, acompanhadas de uma autoestima fragilizada, despotencializam os afetos, enfraquecem o corpo e impedem a experimentação de novos territórios do desejo e do amor. Encontramos aí a segunda linha, a da simulação.

E então, nos perguntamos: será possível não estagnar em nenhuma linha? Será possível um modo diferente de amar? Uma nova suavidade no amor? Talvez, um primeiro ponto na busca por respostas seja ressaltar que, para a esquizoanálise, o desejo não é constituído pela falta, pois para Deleuze e Guattari (1996), o desejo é processo, produção da realidade no social, daí a denominação produção desejante. Não falta para o sujeito o objeto, mas o sujeito é que falta ao desejo, pois é este que o produz, não havendo, pois, sujeito determinado, mas sempre em produção na realidade social.

O exemplo do amor cortês, citado pelos autores em Mil Platôs vol. 3, é paradigmático a esse respeito, pois a postergação dos amantes não pode ser interpretada como a lei da falta, senão por um desejo que preenche a si próprio, incitando a criação de um corpo sem órgãos por onde passam intensidades capazes de diluir o eu e o outro, em virtude das singularidades não egóicas, pois “ (...) se o desejo não tem o prazer por norma, não é em nome de uma falta que seria impossível remediar, mas, ao contrário, em razão de sua positividade, quer dizer, do plano de consistência que ele traça no decorrer do seu processo" (DELEUZE; GUATTARI, 1996, p. 26).

Para Deleuze e Guattari (1996), a dimensão processual do desejo incita o funcionamento da vida na contramão dos modelos hegemônicos e da tirania da moral para a criação de um modo de vida ético, estético e político da existência.

Na parte III de "Ética", Espinosa (1983) desafia pensar nas possibilidades do que pode um corpo, e sua resposta se encontra na experiência, pois segundo o autor, é somente na experimentação que o corpo encontra sua potência. Espinosa provoca e impulsiona à reflexão ao afirmar que do corpo nada sabemos, não sabemos do que o corpo é capaz, pois são infinitas suas possibilidades de composições e decomposições a partir dos encontros com outros corpos. Os encontros entre corpos são os eventos que os afetam, produzindo aumento ou diminuição da potência de agir ou da energia vital, daquilo que os impulsiona a manter sua condição de existência.

Os afetos para este filósofo são as afecções do corpo, capazes de aumentar ou diminuir nossa potência de agir. O que pode um corpo? Um corpo pode afetar e ser afetado. Segundo Espinosa (1983), as afecções surgem do nosso encontro com o outro e com o mundo, encontro esse que provoca uma alteração em nossa potência, fazendo-a aumentar ou diminuir. Se for um 
bom encontro, se houver produção de alegria, a afecção nos leva a experimentar uma maior potência de agir no mundo. Por outro lado, se for um encontro que produz afetos tristes, essa potência de afetar e ser afetado, de agir no mundo, diminui.

Deleuze (2002) adverte, inspirado em Spinoza, que o bom é quando o encontro provoca uma composição em nossos corpos, e mau quando ele provoca uma decomposição.

Definir os seres pelo seu poder de serem afetados, pelas afeç̧ões de que são capazes, pelas excitações a que reagem, aquelas a que permanecem indiferentes, aquelas que excedem o seu poder e os adoecem ou matam. Desse modo, obterse-á uma classificação dos seres por sua potência, ver-se-ão quais os que convêm com outros e quais os que não convêm, quem pode servir de alimento, e quem é social com quem, e sob quais relações (DELEUZE, 2002, p. 53).

Tentar produzir bons encontros em um mundo que nos comunica um turbilhão de afetos tristes diariamente é, para Espinosa, uma questão de ética. Deleuze (2002) defende a necessidade de produção de bons encontros, de associação com pessoas que despertam afetos alegres em nós, que aumentem nossa potência de agir e, com efeito, que possamos também afetar de modo positivo.

Segundo Deleuze (2002) experimentar é lançar-se ao acontecimento, pois não sabemos do que um corpo é capaz senão pela experimentação.

Portanto, no amor, é preciso reconhecer o outro como diferente, como possuidor de espaços desconhecidos, sem querer invadi-los ou conquistá-los, pois não se pode apropriar-se dos devires do outro.

Em consonância com a proposta ética de Espinosa, está a estética da existência de Foucault. A estética da existência pensada como uma ética do cuidado de si, que se efetua em atos e ações para consigo e para com os outros, está implicada diretamente na produção inventiva de si (novas formas de subjetivação), fazendo da sua própria vida uma obra de arte, assim como também está implicada na capacidade de transformação do mundo que o cerca.

As "artes da existência" devem ser entendidas como as práticas racionais e voluntárias pelas quais os homens não apenas determinam para si mesmos regras de conduta, como também buscam transformar-se e modificar seu ser singular, e fazer de sua vida uma obra que seja portadora de certos valores estéticos e que corresponda a certos critérios de estilo. (FOUCAULT, 2001, p. 198-199)

Com a estética da existência e as técnicas de cuidado de si, Foucault nos leva a refletir sobre a necessidade de afirmação da singularidade, de maneiras singulares de cuidar de si e dos outros, inclusive no encontro amoroso, buscando criar novos modos e estilos de se relacionar, dotados do direito à diferença, da capacidade de resistir e escapar dos dispositivos de captura que aprisionam em modelos e identidades hegemônicas.

É preciso compreender que sempre haverá modelos de dominação que tentarão doutrinar e padronizar os modos de viver, de amar, de estudar, de trabalhar, mas ao aceitarmos a vida e a subjetividade como obras em constante processo, permitiremos a libertação através da substituição da moral pela ética, fazendo da vida uma obra de arte.

Deslocar as afetações dos encontros da moral para a ética, também implica modificar o modelo político e o formato das relações sociais.

Para Deleuze e Guattari (1996), são os agenciamentos do desejo que produzem o real. É o agenciamento entendido enquanto conexão e simbiose que constitui as relações entre os corpos e os enunciados. Assim, o desejo é pensado na esfera da produção, como elemento essencial na produção da própria realidade, e não ao nível da representação de um sujeito desejante. 
Portanto, a subjetividade pensada sob o prisma da esquizoanálise é sempre produzida por uma época, por um sistema de relações, ou por uma cultura, e tende, assim, a ser reprodutora de modelos dominantes, ou seja, a subjetividade é atravessada por diversos fatores de subjetivação como instituições, objetos técnicos, saberes etc.; em constante produção e reprodução social.

A subjetividade é produzida por agenciamentos de enunciação. Os processos de subjetivação, de semiotização - ou seja, toda a produção de sentido, de eficiência semiótica - não são centrados em agentes individuais (no funcionamento de instâncias intrapsíquicas, egóicas, microssociais), nem em agentes grupais. Esses processos são duplamente descentrados. Implicam o funcionamento de máquinas de expressão que podem ser tanto de natureza extra-pessoal, extra-individual (sistemas maquínicos, econômicos, sociais, tecnológicos, icônicos, ecológicos, etológicos, de mídia, enfim sistemas que não são mais imediatamente antropológicos), quanto de natureza infra-humana, infrapsíquica, infrapessoal (sistemas de percepção, de sensibilidade, de afeto, de representação, de imagens, de valor, modos de memorização e produção de ideia, sistemas de inibição e de automatismos, sistemas corporais, orgânicos, biológicos, fisiológicos, etc.) (GUATTARI; ROLNIK, 2005. p. 31).

Em outras palavras, a subjetividade é produzida coletivamente, mas não como a somatória de subjetividades individuas, e sim a partir de agenciamentos coletivos de enunciação que se acoplam e se individuam. A individuação da subjetividade, diferente da individualização, é o processo que permite a produção de singularização, rompendo padrões dominantes que serializam e individualizam.

Para se pensar os agenciamentos coletivos de enunciação no capitalismo contemporâneo, Guattari e Rolnik (2005) desenvolveu a noção de micropolítica. O objetivo é compreender como se interpelam os planos molares e moleculares num determinado campo social e de que modo tais entrecruzamentos são capazes de produzir ou reproduzir modos de subjetivação dominantes.

A macropolítica está ligada aos movimentos molares, estratificados e serializantes, cujo principal efeito seria a reprodução e hegemonia dos modelos dominantes. Já a micropolítica está atrelada aos processos moleculares e inventivos, buscando lançar mão de movimentos instituintes e minoritários.

A este respeito, referencia-se Baremblitt (2006) ao elucidar que não é possível estabelecer uma separação radical entre o que é macro e micro, pois ambos coexistem intrinsecamente, podendo ser separados somente de modo artificial para serem estudados. Ou ainda, parafraseando Deleuze e Guattari (1996, p. 99): "Em suma tudo é político, mas toda política é ao mesmo tempo macropolítica e micropolítica".

Deleuze, na entrevista Controle e Devir (2013), afirma que não há nada de universal no capitalismo a não ser o mercado, e que não existe qualquer Estado que não esteja totalmente comprometido em gerar riqueza e miséria, e principalmente produzir subjetividades enquanto misérias humanas.

Para o autor, os processos de subjetivação em indivíduos ou coletividades são potentes na medida em que escapam aos saberes e práticas instituídos e dominantes, e se efetivam através de uma espontaneidade rebelde. E atrelado aos processos de subjetivação, suscita o conceito de acontecimento $^{3}$ e a importância de se aproveitar os momentos em que ele vem à superfície para

\footnotetext{
3 "Em todo acontecimento, há de fato o momento presente da efetuação, aquele em que o acontecimento se encarna em um estado de coisas, um indivíduo, uma pessoa, aquele que é designado quando se diz: pronto, chegou a hora; e o futuro e o passado do acontecimento só são julgados em função desse presente definitivo, do ponto de vista
} 
se criar novos modos de resistência frente ao império do capital e toda perversidade adjacente, pois Deleuze (2013) afirma que uma sociedade se caracteriza por suas linhas de fugas, ou seja, pelo que escapa, que foge, que não está codificado porque é inventivo e é a própria resistência.

Deste modo, em contrapartida aos modos de amar influenciados pelo capitalismo, propomos uma nova suavidade no amor, marcada pela ética da produção de bons encontros, pela estética do cuidado de si e pela criação política de novos modos de subjetivação.

O filósofo Luiz Fuganti, em relação aos modos de vida, vai dizer:

[...] é no modo de vida que está o segredo de qualquer coisa. A pedra de toque da liberdade, da escravidão, do pensamento, da submissão à sabedoria, está sempre no modo de vida. O modo de viver é simultaneamente ético e estético. Ele cria regras éticas, que podem até ser regras morais, e ao mesmo tempo ele expressa um modo da energia ou do desejo atravessar o corpo que faz do corpo e da alma uma expressão estética, uma obra de arte. Ou um trapo (FUGANTI, 2001, p. 2).

Deste modo, pensar uma proposta ética, estética e política para os encontros afetivos, é pensar o amor enquanto acontecimento, onde os encontros corpóreos se passam na superfície sem que sejam superficiais, porque é na superfície que os corpos se encontram e se afetam produzindo acontecimentos que geram desvios e mudanças de sentido.

É necessário fazer escapar os pensamentos e os modos de vida da representação do mundo, das repetições e clichês da memória. $\mathrm{O}$ ato de pensar enquanto singularização é raro, mas permite aproximar a existência dos processos criativos e revolucionários.

Encontrar uma nova suavidade no amor é, portanto, criar uma outra relação com o corpo, fugir de todos os modos de subjetivação que implicam a vontade de poder sobre o corpo do outro. É produzir e experimentar a leveza do amor, sem que tal leveza também se confunda com o descompromisso das máquinas celibatárias.

Amar com suavidade é criar e experimentar devires, que assim como Deleuze e Guattari (1997) já afirmaram, não são da ordem da imitação ou da filiação, e sim do contágio. Encontrar uma nova suavidade é deixar-se contagiar pelos devires moleculares e minoritários, como um devir mulher, um devir animal, um devir criança, e amar com a inocência e o cuidado de um passarinho que ama e é amado por uma flor.

\section{Referências}

BAREMBLITT, G. Trabalho e subjetividade. Belo Horizonte: Fundação Gregório Baremblitt/Instituto Félix Guattari, 2006.

COSTA, J. F. Sem fraude nem favor: estudos sobre o amor romântico. Rio de Janeiro: Rocco, 1998.

\footnotetext{
daquele que o encarna. Mas há, por outro lado, o futuro e o passado do acontecimento tomado em si mesmo, que esquiva todo presente porque está livre das limitações de um estado de coisas, sendo impessoal e pré-individual, neutro, nem geral nem particular, eventum tantum...; ou antes que não tem outro presente senão o do instante móvel que o representa, sempre desdobrado em passado-futuro, formando o que convém chamar de contraefetuação. Em um dos casos, é minha vida que me parece frágil demais para mim, que escapa num ponto tornado presente numa relação determinável comigo. No outro caso, sou eu que sou fraco demais para a vida, a vida é grande demais para mim, lançando por toda a parte suas singularidades, sem relação comigo nem com um momento determinável como presente, salvo com o instante impessoal que se desdobra em ainda-futuro e jápassado." (ZOURABICHVILI, F. O vocabulário de Deleuze, Rio de Janeiro, 2004).
} 
O AMOR E AS RELAÇÕES AFETIVAS NA CONTEMPORANEIDADE - UMA PROPOSTA ÉTICA...

DELEUZE, G. Spinoza: filosofia prática. Trad. Daniel Lins e Fabien Pascal Lins. São Paulo: Ed. Escuta, 2002.

DELEUZE, G. Controle e devir. In: DELEUZE, G. Conversações. 3. ed. Trad. Peter Pál Pelbart. São Paulo: Editora 34, 2013, p. 213-222.

DELEUZE, G; GUATTARI. F. Mil platôs: capitalismo e esquizofrenia, vol. 3. 2. ed. São Paulo: Editora 34, 1996.

DELEUZE, G; GUATTARI, F. Mil platôs: capitalismo e esquizofrenia, vol. 4. 2. ed. São Paulo: Editora 34, 1997.

DELEUZE, G; GUATTARI, F. O anti-édipo: capitalismo e esquizofrenia. São Paulo: Editora 34, 2010.

ESPINOSA, B. Ética. 3. ed. São Paulo: Abril, 1983.

FOUCAULT, M. Ditos e escritos, vol. 3. Rio de Janeiro: Forense Universitária, 2001.

FUGANTI, L. A formação do pensamento ocidental: aula 1 de 29/3/2001. Disponível em: http://escolanomade.org/2016/03/18/aula-1-introducao/. Acesso em: 23 maio 2019.

GUATTARI, F., ROLNIK, S. Micropolíticas: cartografias do desejo. Petrópolis: Editora Vozes, 2005

ROLNIK, S. Cartografia sentimental: transformações contemporâneas do desejo. São Paulo: Estação Liberdade, 1989.

TAKEUTI, N. Amor, nem tão demasiadamente humano nem demasiadamente desumano. Princípios: Revista de Filosofia (UFRN), v. 22, n. 38, p. 63-86, 10 out. 2015. 